\title{
Temperature Profile on the Boundary of Solution Domain for a Potential Problem Using BEM
}

\author{
Muli F.M. ${ }^{1}$, Kinyanjui J.N. ${ }^{2 *}$ \\ ${ }^{1}$ Department of Mathematics and Acturial Science, Karatina University P.O Box 1957-10101 Nyeri \\ ${ }^{2}$ Department of Pure and Applied Science Kirinyaga University, P.O Box 143-10300 Kerugoya
}

\begin{abstract}
Heat diffusion particularly in buried pipes is of great interest in oil and gas industries. This research models heat transfer in square cross-section pipes for simplicity, under isotropic conditions. Heat transfer in the exterior domain of the pipe is investigated to determine temperature profile. The governing equation is then reformulated into BIE using Green's theorem, and due to singularities, BEM is used to discretize the integral equations which are the solved numerically and the results illustrated graphically.
\end{abstract}

Keywords: BIE, BEM, Temperature Profile, Boundary Value Problem

\section{Preliminaries}

\subsection{Notation and Terminology}

U-Temperature in Kelvin:q-Heat flux vector: $\alpha$ - Thermal diffusivity: $\mathrm{k}$-Thermal conductivity: $\mathrm{k}_{\mathrm{x}}(\mathrm{U}), \mathrm{k}_{\mathrm{y}}(\mathrm{U})$ and $\mathrm{k}_{\mathrm{z}}(\mathrm{U})$ are temperature dependent thermal conductivities in the $\mathrm{x}, \mathrm{y}$ and $\mathrm{z}$ directions respectively: $\mathrm{s}$-Surface: $\mathrm{N}$-Number of nodes: $\mathrm{x}, \mathrm{y}$ - Cartesian co-ordinate: $\mathrm{x}_{\mathrm{p}}, \mathrm{y}_{\mathrm{p}}$-Co-ordinates of point $p$ inside the solution domain or at the boundary. $\Gamma_{1}$-The inner boundary of the solution domain: $\Gamma_{2}$-The outer boundary of the solution domain: $\Gamma_{2}$-The outer boundary of the solution domain: $\Gamma=\Gamma_{1} U \Gamma_{2}: R-$ Region enclosed by $\Gamma$. BEM Boundary Element Method:BIE-Boundary Integral Equation: BVP-Boundary Value Problem: PDEPartial Differential Equation

\subsection{Introduction}

BEM is one of the numerical techniques designed for solving BVPs in partial differential equations (PDEs). Integral equations constitute the foundation of the BEM, and have been known for more than a century. In particular, it is known for a long time that the solutions of BVPs can also be expressed as solutions of an integral equation. As early as 1903 Fredholm[4] already used discretized integral equations for potential problems. His work can be considered the basis for the indirect formulation of the BEM; the functions that appear in the indirect formulation do not have a physical meaning, though physical quantities can be derived from these functions.

The breakthrough in the development of the BEM came in the nineteen sixties. Jaswon [8] and Symm [6] discretised the integral equations for two-dimensional potential problems by approximating the boundary of a domain by a set of straight lines. At each line element the functions are approximated by constants. Their method has a semi-direct formulation, as the functions need to be differentiated or integrated to obtain physical quantities. A direct formulation has been introduced by Rizzo [2], who also used discretised integral equations to relate displacements and tractions in two-dimensional elasticity theory.
Yan and Wei[12] carried out research on the impact of soil and pipe thermal conductivities on performance of horizontal buried pipe. They made a conclusion that soil temperature distribution around a buried pipe presents a sine curve regardless of the soil and pipe thermal conductivities. The basic law which gives the relationship between the heat flow and the temperature gradient is due to the French mathematician Jean Baptist Joseph Fourier (1768 - 1830). By Fourier law the rate of heat flow through a surface is proportional to the negative temperature gradient across the surface.

$$
\mathbf{q}=-\mathrm{k} \nabla \mathrm{U}
$$

\section{Governing Equations}

The starting point for our model is the Fourier's Law [3] which specifies that heat transfer is governed by the eqn(1.03).

If our system is in steady-state, then Conservation of Energy [3] implies that, in the absence of heat sinks or sources, the heat flux throughout the region must satisfy:

$$
\nabla \cdot \mathbf{q}=0
$$

In three dimensions the transient heat conduction is given by:

$$
\begin{aligned}
\frac{\partial}{\partial x}\left(k_{x}(U) \frac{\partial U}{\partial x}\right)+ & \frac{\partial}{\partial y}\left(k_{y}(U) \frac{\partial U}{\partial y}\right)+\frac{\partial}{\partial z}\left(k_{z}(U) \frac{\partial U}{\partial z}\right) \\
& +F(x, y, z, t)=\rho c_{p} \frac{\partial U}{\partial t}(3.01 b)
\end{aligned}
$$

In one dimension, this would imply that heat flux must be constant at all points; in more than one dimension, it implies that heat flux entering a control region must equal heat flux leaving the same region. Without any heat generation and considering 2-D heat flow in steady state, the conservation of energy eqn. (3.01b) reduces down to Laplace's equation.

$$
\nabla^{2} \mathrm{U}=0
$$

Or

$$
\frac{\partial^{2} \mathrm{U}}{\partial \mathrm{x}^{2}}+\frac{\partial^{2} \mathrm{U}}{\partial \mathrm{y}^{2}}=0
$$

Since $U$ is frequently a potential function, this equation is also known as potential equation. 


\section{International Journal of Science and Research (IJSR) \\ ISSN (Online): 2319-7064}

Index Copernicus Value (2015): 78.96 | Impact Factor (2015): 6.391

A boundary value problem which is of practical interest requires solving the Laplace equation (3.03) in the two dimensional region $\mathrm{R}$ bounded by a simple closed curve Tsubject to the boundary conditions

$$
\begin{aligned}
& \quad U=f_{1}(x, y) \text { for }(x, y) \in \Gamma_{1} \\
& \frac{\partial U}{\partial n}=f_{2}(x, y) \text { for }(x, y) \in \Gamma_{2}
\end{aligned}
$$

wheref $f_{1}$ and $f_{2}$ are suitably prescribed functions and $\Gamma_{1}$ and $\Gamma_{2}$ are non-intersecting curves such that $\Gamma_{1} U \Gamma_{2}=\Gamma$

It is worth noting that the Laplace equation is both linear and homogeneous while the boundary conditions we are specifying are linear and non-homogeneous. This creates a problem because separation of variables requires homogeneous boundary conditions.

The boundary conditions in eqn. (3.04)imply that at each and every point on the boundary, either the temperature or the heat flux (but not both) is known. To determine the temperature field in the region $\mathrm{R}$, one has to solve eqn.(3.03)to find the solution that satisfies the prescribed boundary condition on $\Gamma$.

The normal derivative $\frac{\partial \mathrm{U}}{\partial \mathrm{n}}$ is defined by

$$
\frac{\partial \mathrm{U}}{\partial \mathrm{n}}=\mathrm{n}_{\mathrm{x}} \frac{\partial \mathrm{U}}{\partial \mathrm{x}}+\mathrm{n}_{\mathrm{y}} \frac{\partial \mathrm{U}}{\partial \mathrm{y}}
$$

Here the unit normal vector $\left[\mathrm{n}_{\mathrm{x}}, \mathrm{n}_{\mathrm{y}}\right]$ on $\Gamma$ is taken to be pointing away from the region $\mathrm{R}$. It is worth noting that the vector may vary from point to point on $\Gamma$. Thus, $\left[n_{x}, n_{y}\right]$ is a function of $\mathrm{x}$ and $\mathrm{y}$.

The boundary conditions prescribed in eqn.(3.04) are assumed to be well posed so that the boundary value problem has a unique solution, that is, it is assumed that one can always find a function $\mathrm{U}(\mathrm{x}, \mathrm{y})$ satisfying eqns.(3.03) and (3.04) and that there is only one such function.

In general, it is difficult (if not impossible) to solve exactly the BVP defined by eqns.(3.03) - (3.04). The mathematical complexity depends on the geometrical shape of the region $\mathrm{R}$ and the boundary conditions given in (3.04).

Exact solutions can only be found for relatively simple geometries ofR (such as square and circular regions) together with particular boundary conditions. For more complicated geometries, one may have to resort to numerical (approximate) techniques.

\subsection{The transformation from Cartesian coordinates to polar coordinates}

We consider eqn(3.03) above and the parametric equations: $x=r \cos \theta$ and $y=r \sin \theta$; where $r$ is the radius of the pipe and thus a constant. We therefore have the laplace equation (3.03) in polar form as

$$
\frac{\partial^{2} \mathrm{U}}{\partial \mathrm{r}^{2}}+\frac{1}{\mathrm{r}} \frac{\partial \mathrm{U}}{\partial \mathrm{r}}+\frac{1}{\mathrm{r}^{2}} \frac{\partial^{2} \mathrm{U}}{\partial \theta^{2}}=0
$$

Eqn. (3.14) is independent of $\theta$, hence it becomes;

$$
\frac{\partial^{2} \mathrm{U}}{\partial \mathrm{r}^{2}}+\frac{1}{\mathrm{r}} \frac{\partial \mathrm{U}}{\partial \mathrm{r}}=0
$$

Whose solution is: $\mathrm{U}(\mathrm{r})=\mathrm{A} \ln r+\mathrm{B}$

Where A and B these can be determined if we know U(r) and $\frac{\partial U}{\partial r}$ on the boundary of the pipe.. This solution blows up as $r \rightarrow \infty$ so it is only of limited interest in estimating the temperature distribution near the pipe. When the boundary at ground level is introduced, it becomes clear wecannot parameterize the solution by $r$ alone. The purpose of highlighting this solution is that it provides the basis for the Fundamental Solution of Laplace's Equation.

\subsection{Fundamental solutions}

To derive this fundamental solution, we consider the Laplace equation $\nabla^{2} U=0$ in $\mathbb{R}^{2}$ which contains singularity at the point $\left(\mathrm{x}_{\mathrm{p}}, \mathrm{y}_{\mathrm{p}}\right)$. We expect the solution to be symmetric about this point $\left(\mathrm{x}_{\mathrm{p}}, \mathrm{y}_{\mathrm{p}}\right)$, since $\delta\left(\mathrm{x}_{\mathrm{p}}-\mathrm{x}, \mathrm{y}_{\mathrm{p}}-\mathrm{y}\right)$ is symmetric about this point. We thus adopt a local polar coordinates system about the singular point $\left(\mathrm{x}_{\mathrm{p}}, \mathrm{y}_{\mathrm{p}}\right)$.

Let $r=\sqrt{\left(x_{p}-x\right)^{2}+\left(y_{p}-y\right)^{2}}$

The Laplace equation in polar coordinates is:

$$
\frac{1}{\mathrm{r}} \frac{\partial}{\partial \mathrm{r}}\left(\mathrm{r} \frac{\partial \mathrm{U}}{\partial \mathrm{r}}\right)+\frac{1}{\mathrm{r}^{2}} \frac{\partial^{2} \mathrm{U}}{\partial \theta^{2}}=0
$$

For $r>0, \delta\left(x_{p}-x, y_{p}-y\right)=0$ and owing to the symmetry, $\frac{\partial^{2} U}{\partial \theta^{2}}$ is zero. The equation above becomes: $\frac{1}{\mathrm{r}} \frac{\partial}{\partial \mathrm{r}}\left(\mathrm{r} \frac{\partial \mathrm{U}}{\partial \mathrm{r}}\right)=\frac{\partial^{2} \mathrm{U}}{\partial \mathrm{r}^{2}}+\frac{1}{\mathrm{r}} \frac{\partial \mathrm{U}}{\partial \mathrm{r}}=0$ which has solution $\mathrm{U}=\mathrm{Bln} \mathrm{r}+$ $\mathrm{A}$ with $\mathrm{A}$ and $\mathrm{B}$ constant. We put $\mathrm{A}=0$ and to determine the constant B, we apply Green's theorem to U and 1 in a small disc $D_{r}$ (with boundary $C_{r}$ ), of radius $r$ around the origin $\left(\mathrm{x}_{\mathrm{p}}, \mathrm{y}_{\mathrm{p}}\right)$.

It can be shown that $\nabla^{2} \mathrm{G}=-\delta(\mathrm{x}-\varepsilon)$ in $\mathrm{V}$.

$$
\int_{\Gamma_{\mathrm{r}}} \frac{\partial \mathrm{v}}{\partial \mathrm{n}} \mathrm{dS}=\int_{\mathrm{D}_{\mathrm{r}}} \nabla^{2} \mathrm{vdV}=-\int_{\mathrm{D}_{\mathrm{r}}} \delta(\mathrm{x}-\varepsilon) \mathrm{dV}=-1
$$

We now choose $B$ to make $\int_{\Gamma_{\mathrm{r}}} \frac{\partial \mathrm{v}}{\partial \mathrm{n}} \mathrm{dS}=-1$.

In polar coordinates $\frac{\partial \mathrm{v}}{\partial \mathrm{n}}=\frac{\partial \mathrm{v}}{\partial \mathrm{r}}=\frac{\mathrm{B}}{\mathrm{r}}$ and $\mathrm{dS}=\mathrm{rd} \theta$ (going around circle $\Gamma_{\mathrm{r}}$ ). Hence :

$\int_{0}^{2 \pi} \frac{B}{r} r d \theta=B \int_{0}^{2 \pi} d \theta=-1 . \quad$ This implies that $B=-\frac{1}{2 \pi}$ This gives $\mathrm{v}=-\frac{1}{2 \pi} \ln \mathrm{r}$ which can be written as: $\mathrm{v}=$ $-\frac{1}{4 \pi} \ln r^{2}$. Hence;

$$
\mathrm{v}=-\frac{1}{4 \pi} \ln \left[\left(\mathrm{x}_{\mathrm{p}}-\mathrm{x}\right)^{2}+\left(\mathrm{y}_{\mathrm{p}}-\mathrm{y}\right)^{2}\right]
$$

We replace $v$ with $G$ to get

$$
G\left(x, y \mid x_{p}, y_{p}\right)=-\frac{1}{4 \pi}\left[\left(x_{p}-x\right)^{2}+\left(y_{p}-y\right)^{2}\right]
$$

which is the fundamental solution of 2-D Laplace equation at a point $\mathrm{p}=\left(\mathrm{x}_{\mathrm{p}}, \mathrm{y}_{\mathrm{p}}\right)$

$\mathrm{G}$ is defined everywhere in $\mathbb{R}^{2}$ apart from at $\left(\mathrm{x}_{\mathrm{p}}, \mathrm{y}_{\mathrm{p}}\right)$ where it is singular. We can now transform the PDE eqn. (3.15) into a Boundary Integral Equation (BIE) which we can solve numerically on the boundary of the pipe. 


\section{International Journal of Science and Research (IJSR) \\ ISSN (Online): 2319-7064}

Index Copernicus Value (2015): 78.96 | Impact Factor (2015): 6.391

\subsection{Reciprocal relation}

If $U_{1}$ and $U_{2}$ are two solutions of eqn.(3.03) in the region $R$, bounded by simple closed curve $\Gamma$, then it can be shown that:

$$
\int_{\Gamma}\left(\mathrm{U}_{2} \frac{\partial \mathrm{U}_{1}}{\partial \mathrm{n}}-\mathrm{U}_{1} \frac{\partial \mathrm{U}_{2}}{\partial \mathrm{n}}\right) \mathrm{ds}(\mathrm{x}, \mathrm{y})=0
$$

By substituting eqn.(3.05)

Equation (3.26) above provides a reciprocal relation between any two solutions of Laplace's equation in the region $\mathrm{R}$ bounded by the curve $\Gamma$.

We derive this reciprocal relation from the two-dimensional version of divergence theorem.

According to the divergence theorem, if $\mathbf{F}=\mathrm{u}(\mathrm{x}, \mathrm{y}) \mathbf{i}+$ $\mathrm{v}(\mathrm{x}, \mathrm{y}) \mathbf{j}$ is a well-defined function such that $\widetilde{\nabla} \cdot \tilde{\mathrm{F}}=\frac{\partial \mathrm{u}}{\partial \mathrm{x}}+\frac{\partial \mathrm{v}}{\partial \mathrm{y}}$ exists in the region bounded by the simple closed curve $\Gamma$, then

$$
\begin{aligned}
& \int_{\Gamma} \text { F. n ds }(\mathrm{x}, \mathrm{y}) \\
& =\iint_{\mathrm{R}} \nabla \cdot \mathrm{Fdxdy}
\end{aligned}
$$

This implies that

$$
\int_{\Gamma}\left[\mathrm{un}_{\mathrm{x}}+\mathrm{vn}_{\mathrm{y}}\right] \mathrm{ds}(\mathrm{x}, \mathrm{y})=\iint_{\mathrm{R}}\left[\frac{\partial \mathrm{u}}{\partial \mathrm{x}}+\frac{\partial \mathrm{u}}{\partial \mathrm{y}}\right] \mathrm{dxdy}
$$

Where $\mathbf{n}=\left[\mathrm{n}_{\mathrm{x}}, \mathrm{n}_{\mathrm{y}}\right]$ is the unit normal vector to the curve $\Gamma$, pointing away from region $\mathrm{R}$.

Since $U_{1}$ and $U_{2}$ are solutions to eqn.(3.03) i.e the Laplace equation, we can write

$$
\begin{aligned}
& \frac{\partial^{2} \mathrm{U}_{1}}{\partial \mathrm{x}^{2}}+\frac{\partial^{2} \mathrm{U}_{1}}{\partial \mathrm{y}^{2}} \\
& =0 \\
& \frac{\partial^{2} \mathrm{U}_{2}}{\partial \mathrm{x}^{2}}+\frac{\partial^{2} \mathrm{U}_{2}}{\partial \mathrm{y}^{2}}
\end{aligned}
$$

$=0$

If we multiply the first equation by $\mathrm{U}_{2}$ and the second one by $\mathrm{U}_{1}$ and take the difference of the resulting equations, we obtain

$$
\begin{gathered}
\frac{\partial}{\partial \mathrm{x}}\left(\mathrm{U}_{2} \frac{\partial \mathrm{U}_{1}}{\partial \mathrm{x}}-\mathrm{U}_{1} \frac{\partial \mathrm{U}_{2}}{\partial \mathrm{x}}\right)+\frac{\partial}{\partial \mathrm{y}}\left(\mathrm{U}_{2} \frac{\partial \mathrm{U}_{1}}{\partial \mathrm{y}}-\mathrm{U}_{1} \frac{\partial \mathrm{U}_{2}}{\partial \mathrm{y}}\right) \\
=0
\end{gathered}
$$

which we can integrate over $\mathrm{R}$ to give

$$
\begin{gathered}
\iint_{\mathrm{R}}\left[\frac{\partial}{\partial \mathrm{x}}\left(\mathrm{U}_{2} \frac{\partial \mathrm{U}_{1}}{\partial \mathrm{x}}-\mathrm{U}_{1} \frac{\partial \mathrm{U}_{2}}{\partial \mathrm{x}}\right)+\frac{\partial}{\partial \mathrm{y}}\left(\mathrm{U}_{2} \frac{\partial \mathrm{U}_{1}}{\partial \mathrm{y}}-\mathrm{U}_{1} \frac{\partial \mathrm{U}_{2}}{\partial \mathrm{y}}\right)\right] \mathrm{dxdy} \\
=0
\end{gathered}
$$

An application of the divergence theorem to convert the double integral over $\mathrm{R}$ into a line integral over $\Gamma$ gives

$$
\begin{aligned}
\int_{\Gamma}\left[\left(\mathrm{U}_{2} \frac{\partial \mathrm{U}_{1}}{\partial \mathrm{x}}-\mathrm{U}_{1}\right.\right. & \left.\frac{\partial \mathrm{U}_{2}}{\partial \mathrm{x}}\right) \mathrm{n}_{\mathrm{x}} \\
& \left.+\left(\mathrm{U}_{2} \frac{\partial \mathrm{U}_{1}}{\partial \mathrm{y}}-\mathrm{U}_{1} \frac{\partial \mathrm{U}_{2}}{\partial \mathrm{y}}\right) \mathrm{n}_{\mathrm{y}}\right] \mathrm{ds}(\mathrm{x}, \mathrm{y}) \\
& =0
\end{aligned}
$$

Which is essentially eqn.(3.26).

\section{Direct Boundary Element Method}

The choice of BEM is informed by the fact that it can be applied where any potential problem is governed by a differential equation that satisfies the Laplace equation.

Given the advantages of this approach, we shall now use this method to obtain a solution for eqn. (3.15). There are a couple of different ways this can be done via the Direct Method (which solves for $U$ and $\frac{\partial U}{\partial N}$ directly) or the Indirect Method (which solves for a density function which then generates solutions for $\mathrm{U}$ ). We shall use the Direct Method because in this case it has the advantage of immediately yielding the boundary temperature, which we will then use to generate temperature profiles on the boundary.

To derive the boundary integral equation we let $U_{1}=$ $\mathrm{G}\left(\mathrm{x}, \mathrm{y} ; \mathrm{x}_{\mathrm{p}}, \mathrm{y}_{\mathrm{p}}\right)$ (the fundamental solution defined in eqn.(3.25) and $U_{2}=U$, where $U$ is the required solution of the boundary value problem defined by eqn.(3.03) and (3.04).

Since $G\left(x, y ; x_{p}, y_{p}\right)$ is not well defined at the point $\left(x_{p}, y_{p}\right)$, the reciprocal relation in eqn.(3.26) is valid for $U_{1}=$ $\mathrm{G}\left(\mathrm{x}, \mathrm{y} ; \mathrm{x}_{\mathrm{p}}, \mathrm{y}_{\mathrm{p}}\right)$ and $\mathrm{U}_{2}=\mathrm{U}$ only if $\left(\mathrm{x}_{\mathrm{p}}, \mathrm{y}_{\mathrm{p}}\right)$ does not lie in the region $\mathrm{R} U \mathrm{\Gamma}$. Thus

$$
\begin{aligned}
\int_{\Gamma}\left[\mathrm{U}(\mathrm{x}, \mathrm{y}) \frac{\partial}{\partial \mathrm{n}}\left(\mathrm{G}\left(\mathrm{x}, \mathrm{y} ; \mathrm{x}_{\mathrm{p}}, \mathrm{y}_{\mathrm{p}}\right)\right)\right. \\
\left.\quad \mathrm{G}\left(\mathrm{x}, \mathrm{y} ; \mathrm{x}_{\mathrm{p}}, \mathrm{y}_{\mathrm{p}}\right) \frac{\partial}{\partial \mathrm{n}}(\mathrm{U}(\mathrm{x} . \mathrm{y}))\right] \mathrm{ds}(\mathrm{x}, \mathrm{y}) \\
=0 \\
\text { for }\left(\mathrm{x}_{\mathrm{p}}, \mathrm{y}_{\mathrm{p}}\right) \notin \mathrm{R} \mathrm{U} \Gamma
\end{aligned}
$$

For the case in which $\left(x_{p}, y_{p}\right)$ lies in the region $R$, eqn.(3.26) is valid if we replace $\Gamma$ by $\Gamma U \Gamma_{\varepsilon}$, where $\Gamma_{\varepsilon}$ is a circle of centre $\left(x_{p}, y_{p}\right)$ and radius $\varepsilon$. This is because $\mathrm{G}\left(\mathrm{x}, \mathrm{y} ; \mathrm{x}_{\mathrm{p}}, \mathrm{y}_{\mathrm{p}}\right)$ and its first order partial derivatives (with respect to $\mathrm{x}$ or $\mathrm{y})$ are well defined in the region between $\Gamma$ and $\Gamma_{\varepsilon}$. Thus we can write

$$
\begin{aligned}
\int_{\Gamma U \Gamma_{\varepsilon}}\left[U(x, y) \frac{\partial}{\partial n}\right. & \left(G\left(x, y ; x_{p}, y_{p}\right)\right) \\
& \left.-G\left(x, y ; x_{p}, y_{p}\right) \frac{\partial}{\partial n}(U(x . y))\right] d s(x, y) \\
& =0
\end{aligned}
$$

This implies that

$$
\begin{aligned}
& \int_{\Gamma}\left[U(x, y) \frac{\partial}{\partial n}\left(G\left(x, y ; x_{p}, y_{p}\right)\right)\right. \\
& \left.\quad-G\left(x, y ; x_{p}, y_{p}\right) \frac{\partial}{\partial n}(U(x . y))\right] d s(x, y) \\
& \quad= \\
& -\int_{\Gamma_{\varepsilon}}\left[U(x, y) \frac{\partial}{\partial n}\left(G\left(x, y ; x_{p}, y_{p}\right)\right)\right. \\
& \left.-G\left(x, y ; x_{p}, y_{p}\right) \frac{\partial}{\partial n}(U(x . y))\right] d s(x, y)
\end{aligned}
$$

It is worth noting that the divergence theorem is not only applicable for the simply connected regions but also for multiply connected ones as in the case of this study. The unit

\section{Volume 6 Issue 7, July 2017 www.ijsr.net}




\section{International Journal of Science and Research (IJSR) \\ ISSN (Online): 2319-7064 \\ Index Copernicus Value (2015): 78.96 | Impact Factor (2015): 6.391}

normal vector to $\Gamma_{\varepsilon}$ (the inner boundary) points towards the centre of the circle).

Equation (3.28) holds for any radius $\varepsilon>0$, so long as the circle $\Gamma_{\varepsilon}$ lies completely inside the region bounded by $\Gamma$. We can let $\varepsilon \rightarrow 0^{+}$in the eqn.(3.28). this gives

$$
\begin{aligned}
& \int_{\Gamma}\left[\mathrm{U}(\mathrm{x}, \mathrm{y}) \frac{\partial}{\partial \mathrm{n}}\left(\mathrm{G}\left(\mathrm{x}, \mathrm{y} ; \mathrm{x}_{\mathrm{p}}, \mathrm{y}_{\mathrm{p}}\right)\right)\right. \\
& \left.-\mathrm{G}\left(\mathrm{x}, \mathrm{y} ; \mathrm{x}_{\mathrm{p}}, \mathrm{y}_{\mathrm{p}}\right) \frac{\partial}{\partial \mathrm{n}}(\mathrm{U}(\mathrm{x} . \mathrm{y}))\right] \mathrm{ds}(\mathrm{x}, \mathrm{y}) \\
& = \\
& -\lim _{\varepsilon \rightarrow 0^{+}} \int_{\Gamma_{\varepsilon}}\left[\mathrm{U}(\mathrm{x}, \mathrm{y}) \frac{\partial}{\partial \mathrm{n}}\left(\mathrm{G}\left(\mathrm{x}, \mathrm{y} ; \mathrm{x}_{\mathrm{p}}, \mathrm{y}_{\mathrm{p}}\right)\right)\right. \\
& \left.-\mathrm{G}\left(\mathrm{x}, \mathrm{y} ; \mathrm{x}_{\mathrm{p}}, \mathrm{y}_{\mathrm{p}}\right) \frac{\partial}{\partial \mathrm{n}}(\mathrm{U}(\mathrm{x} . \mathrm{y}))\right] \mathrm{d} s(\mathrm{~s}, \mathrm{y})
\end{aligned}
$$

Using polar coordinates $r$ and $\theta$ centered about $\left(x_{p}, y_{p}\right)$ as defined by $\mathrm{x}-\mathrm{x}_{\mathrm{p}}=\mathrm{r} \cos \theta$ and $\mathrm{y}-\mathrm{y}_{\mathrm{p}}=\mathrm{r} \sin \theta$, we can write

$$
\begin{aligned}
& \mathrm{G}\left(\mathrm{x}, \mathrm{y} ; \mathrm{x}_{\mathrm{p}}, \mathrm{y}_{\mathrm{p}}\right) \\
& =\frac{1}{2 \pi} \ln (\mathrm{r}) \\
& \quad \frac{\partial}{\partial \mathrm{n}}\left[\mathrm{G}\left(\mathrm{x}, \mathrm{y} ; \mathrm{x}_{\mathrm{p}}, \mathrm{y}_{\mathrm{p}}\right)\right] \\
& \quad=\mathrm{n}_{\mathrm{x}} \frac{\partial}{\partial \mathrm{x}}\left[\mathrm{G}\left(\mathrm{x}, \mathrm{y} ; \mathrm{x}_{\mathrm{p}}, \mathrm{y}_{\mathrm{p}}\right)\right] \\
& \quad+\mathrm{n}_{\mathrm{y}} \frac{\partial}{\partial \mathrm{y}}\left[\mathrm{G}\left(\mathrm{x}, \mathrm{y} ; \mathrm{x}_{\mathrm{p}}, \mathrm{y}_{\mathrm{p}}\right)\right]
\end{aligned}
$$

We evaluate the terms on the right hand side.

$$
\begin{aligned}
\frac{\partial}{\partial x}\left[G\left(x, y ; x_{p}, y_{p}\right)\right] & =\frac{1}{2 \pi} \frac{\partial}{\partial x}\left\{\ln \left[\left(x-x_{p}\right)^{2}+\left(y-y_{p}\right)^{2}\right]\right\} \\
& =\frac{x-x_{p}}{2 \pi r^{2}}=\frac{\cos \theta}{2 \pi r}
\end{aligned}
$$

Similarly

$$
\frac{\partial}{\partial y}\left[G\left(x, y ; x_{p}, y_{p}\right)\right]=\frac{\sin \theta}{2 \pi r}
$$

Hence eqn.(3.30b) becomes

$$
\frac{\partial}{\partial \mathrm{n}}\left[\mathrm{G}\left(\mathrm{x}, \mathrm{y} ; \mathrm{x}_{\mathrm{p}}, \mathrm{y}_{\mathrm{p}}\right)\right]=\frac{\mathrm{n}_{\mathrm{x}} \cos \theta+\mathrm{n}_{\mathrm{y}} \sin \theta}{2 \pi \mathrm{r}}
$$

The Taylor series of $U(x, y)$ about the point $\left(x_{p}, y_{p}\right)$ is given

$$
\operatorname{byU}(\mathrm{x}, \mathrm{y})=\left.\sum_{\mathrm{m}=0}^{\infty} \sum_{\mathrm{k}=0}^{\mathrm{m}}\left(\frac{\partial^{\mathrm{m}} \mathrm{U}}{\partial \mathrm{x}^{\mathrm{k}} \partial \mathrm{y}^{\mathrm{m}-\mathrm{k}}}(\mathrm{U}(\mathrm{x}, \mathrm{y}))\right)\right|_{(\mathrm{x}, \mathrm{y})=\left(\mathrm{x}_{\mathrm{p}}, \mathrm{y}_{\mathrm{p}}\right)} \frac{\left(\mathrm{x}-\mathrm{x}_{\mathrm{p}}\right)^{\mathrm{k}}\left(\mathrm{y}-\mathrm{y}_{\mathrm{p}}\right)^{\mathrm{m}-\mathrm{k}}}{\mathrm{k} !(\mathrm{m}-\mathrm{k}) !}
$$

On the circle $\Gamma_{\varepsilon}, r=\varepsilon$. Thus

$$
\begin{aligned}
\mathrm{U}(\mathrm{x}, \mathrm{y})= & \left.\sum_{\mathrm{m}=0}^{\infty} \sum_{\mathrm{k}=0}^{\mathrm{m}}\left(\frac{\partial^{\mathrm{m}} \mathrm{U}}{\partial \mathrm{x}^{\mathrm{k}} \partial \mathrm{y}^{\mathrm{m}-\mathrm{k}}}(\mathrm{U}(\mathrm{x}, \mathrm{y}))\right)\right|_{(\mathrm{x}, \mathrm{y})=\left(\mathrm{x}_{\mathrm{p}}, \mathrm{y}_{\mathrm{p}}\right)} \frac{\varepsilon^{\mathrm{m}} \cos ^{\mathrm{k}} \theta \sin ^{\mathrm{m}-\mathrm{k}} \theta}{\mathrm{k} !(\mathrm{m}-\mathrm{k}) !} \\
& \text { for }(\mathrm{x}, \mathrm{y}) \in \Gamma_{\varepsilon}
\end{aligned}
$$

Similarly we have

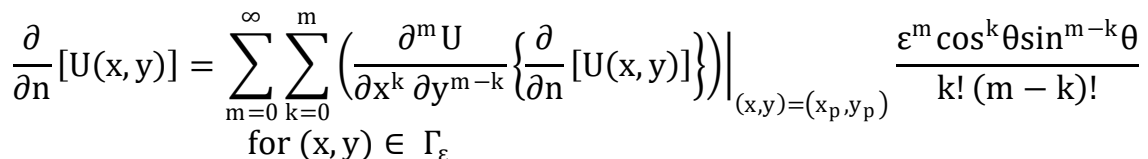

using equations (3.30c), (3.31) and (3.32) and writing $\mathrm{ds}(\mathrm{x}, \mathrm{y})=\varepsilon \mathrm{d} \theta$ with $\theta$ ranging from 0 to $2 \pi$, we attempt to evaluate the limits on the right hand side of eqn.(3.29).

On $\Gamma_{\varepsilon}$, the normal vector $\left[\mathrm{n}_{\mathrm{x}}, \mathrm{n}_{\mathrm{y}]}\right.$ is given by $[-\cos \theta,-\sin \theta]$. We also utilize trigonometric identity $\cos ^{2} \theta+\sin ^{2} \theta=1$ to get.

$$
\begin{gathered}
\int_{\Gamma_{\varepsilon}} U(x, y) \frac{\partial}{\partial n}\left[G\left(x, y ; x_{p}, y_{p}\right)\right] d s(x, y) \\
=-\frac{1}{2 \pi} U\left(x_{p}, y_{p}\right) \int_{0}^{2 \pi} \mathrm{d} \theta \\
\left.-\left.\frac{1}{2 \pi} \sum_{m=1}^{\infty} \sum_{k=0}^{m} \frac{\varepsilon^{m}}{k !(m-k) !}\left(\frac{\partial^{m} U}{\partial x^{k} \partial y^{m-k}}\right)\right|_{(x, y)=\left(x_{p}, y_{p}\right)}\right)_{0}-U\left(x_{p}, y_{p}\right) a s \varepsilon \rightarrow 0^{+}(3.33) \\
\int_{\Gamma_{\varepsilon}} G\left(x, y ; x_{p}, y_{p}\right) \frac{\partial}{\partial n}[U(x, y)] d s(x, y) \\
=\left.\frac{1}{2 \pi} \sum_{m=1}^{\infty} \sum_{k=0}^{m}\left(\frac{\partial^{m} U}{\partial x^{k} y^{m-k}}\left\{\frac{\partial}{\partial n}[U(x, y)]\right\}\right)\right|_{(x, y)=\left(x_{p}, y_{p}\right)}
\end{gathered}
$$

and
Consequently, as $\varepsilon \rightarrow 0^{+}$, equation (3.29) becomes

$$
\begin{array}{r}
U\left(x_{p}, y_{p}\right)=\int_{\Gamma}\left[U(x, y) \frac{\partial}{\partial n}\left(G\left(x, y ; x_{p}, y_{p}\right)\right)\right. \\
\left.-G\left(x, y ; x_{p}, y_{p}\right) \frac{\partial}{\partial n}(U(x . y))\right] d s(x, y) \\
\quad \text { for }\left(x_{p}, y_{p}\right)
\end{array}
$$

$\in \mathrm{R}$

Together with the fundamental eqn.(3.31), eqn.(3.29) provides us with a boundary integral solution for 2-D Laplace's equation.

If both $U$ and $\frac{\partial U}{\partial n}$ are known at all points on $\Gamma$, the line integral in eqn.(3.35) can be evaluated to calculate $U$ at any point $\left(x_{p}, y_{p}\right)$ in the interior of $R$. From the boundary conditions (3.04), at any given point on $\Gamma$, either $U$ or $\frac{\partial U}{\partial n}$, not both, is known. To solve the interior boundary problem, 


\section{International Journal of Science and Research (IJSR) \\ ISSN (Online): 2319-7064}

Index Copernicus Value (2015): 78.96 | Impact Factor (2015): 6.391

we must find the unknowns either $U$ or $\frac{\partial U}{\partial n}$ on the outer and inner boundaries.

Rather than having an expression relating the value of $U$ at some point inside the domain to boundary integrals, a more useful expression would be one relating the value of $U$ at some point on the boundary to boundary integrals.

In case the point $\left(x_{p}, y_{p}\right)$ lies on $\Gamma$, eqn.(3.29) holds if we replace the curve $\Gamma$ by $\mathrm{D} \mathrm{U} \mathrm{D}_{\varepsilon}$

If $\Gamma_{\varepsilon}$ is the circle of centre $\left(\mathrm{x}_{\mathrm{p}}, \mathrm{y}_{\mathrm{p}}\right)$ and radius $\varepsilon$, then $\mathrm{D}$ is part of $\Gamma$ that lies outside $\Gamma_{\varepsilon}$ and $D_{\varepsilon}$ is part of $\Gamma_{\varepsilon}$ that lies inside $\mathrm{R}$. Thus

$$
\begin{aligned}
& \int_{D}\left[U(x, y) \frac{\partial}{\partial n}\left(G\left(x, y ; x_{p}, y_{p}\right)\right)\right. \\
& \left.\quad-G\left(x, y ; x_{p}, y_{p}\right) \frac{\partial}{\partial n}(U(x . y))\right] d s(x, y) \\
& =-\int_{D_{\varepsilon}}\left[U(x, y) \frac{\partial}{\partial n}\left(G\left(x, y ; x_{p}, y_{p}\right)\right)\right. \\
& \left.-G\left(x, y ; x_{p}, y_{p}\right) \frac{\partial}{\partial n}(U(x . y))\right] d s(x, y)
\end{aligned}
$$

As $\varepsilon \rightarrow 0^{+}$, the curve $D$ in eqn.(3.36) tends to $\Gamma$. Thus we write

$$
\begin{aligned}
& \int_{\Gamma}\left[\mathrm{U}(\mathrm{x}, \mathrm{y}) \frac{\partial}{\partial \mathrm{n}}\left(\mathrm{G}\left(\mathrm{x}, \mathrm{y} ; \mathrm{x}_{\mathrm{p}}, \mathrm{y}_{\mathrm{p}}\right)\right)\right. \\
& \left.\quad-\mathrm{G}\left(\mathrm{x}, \mathrm{y} ; \mathrm{x}_{\mathrm{p}}, \mathrm{y}_{\mathrm{p}}\right) \frac{\partial}{\partial \mathrm{n}}(\mathrm{U}(\mathrm{x} . \mathrm{y}))\right] \mathrm{ds}(\mathrm{x}, \mathrm{y}) \\
& =-\lim _{\varepsilon \rightarrow 0^{+}} \int_{\mathrm{D}_{\varepsilon}}\left[\mathrm{U}(\mathrm{x}, \mathrm{y}) \frac{\partial}{\partial \mathrm{n}}\left(\mathrm{G}\left(\mathrm{x}, \mathrm{y} ; \mathrm{x}_{\mathrm{p}}, \mathrm{y}_{\mathrm{p}}\right)\right)\right. \\
& \left.-\mathrm{G}\left(\mathrm{x}, \mathrm{y} ; \mathrm{x}_{\mathrm{p}}, \mathrm{y}_{\mathrm{p}}\right) \frac{\partial}{\partial \mathrm{n}}(\mathrm{U}(\mathrm{x} . \mathrm{y}))\right] \mathrm{ds}(\mathrm{x}, \mathrm{y})
\end{aligned}
$$

We expect $D_{\varepsilon}$ to tend to a semi-circle as $\varepsilon \rightarrow 0^{+}$, if $\left(x_{p}, y_{p}\right)$ lies on a smooth part of $\Gamma$. It then follows that in attempting to evaluate the limit on the right hand side of eqn.(3.36), we have to integrate over only half a circle.

Eqns(3.33) and (3.34) becomes

$$
\begin{gathered}
\lim _{\varepsilon \rightarrow 0^{+}} \int_{D_{\varepsilon}} U(x, y) \frac{\partial}{\partial n}\left[G\left(x, y ; x_{p}, y_{p}\right)\right] d s(x, y) \\
=-\frac{1}{2} U\left(x_{p}, y_{p}\right), \\
\lim _{\varepsilon \rightarrow 0^{+}} \int_{D_{\varepsilon}} G\left(x, y ; x_{p}, y_{p}\right) \frac{\partial}{\partial n}[U(x, y)] d s(x, y) \\
=0
\end{gathered}
$$

Hence eqn. (3.37)becomes

$$
\begin{aligned}
\frac{1}{2} \mathrm{U}\left(\mathrm{x}_{\mathrm{p}}, \mathrm{y}_{\mathrm{p}}\right)=\int_{\Gamma} & {\left[\mathrm{U}(\mathrm{x}, \mathrm{y}) \frac{\partial}{\partial \mathrm{n}}\left(\mathrm{G}\left(\mathrm{x}, \mathrm{y} ; \mathrm{x}_{\mathrm{p}}, \mathrm{y}_{\mathrm{p}}\right)\right)\right.} \\
& \left.-\mathrm{G}\left(\mathrm{x}, \mathrm{y} ; \mathrm{x}_{\mathrm{p}}, \mathrm{y}_{\mathrm{p}}\right) \frac{\partial}{\partial \mathrm{n}}(\mathrm{U}(\mathrm{x} . \mathrm{y}))\right] \mathrm{ds}(\mathrm{x}, \mathrm{y})
\end{aligned}
$$

for $\left(x_{p}, y_{p}\right)$ lying on a smooth part of $\Gamma$

Together with the boundary conditions in eqn.(3.04), eqn. (3.38)can be utilized to obtain a numerical procedure for determining the unknown $U$ and/ or $\frac{\partial U}{\partial n}$ on the boundary
$\Gamma$. Once $U$ and $\frac{\partial U}{\partial n}$ are known at all points on $\Gamma$, the solution of the interior boundary value problem defined eqns(3.03)(3.04) is given by eqn.(3.35) at any point $\left(\mathrm{x}_{\mathrm{p}}, \mathrm{y}_{\mathrm{p}}\right)$ inside $\mathrm{R}$.

For convenience, we may write equations (3.27),(3.35)and (3.38) as a single equation given as

$$
\begin{aligned}
\beta\left(\mathrm{x}_{\mathrm{p}}, \mathrm{y}_{\mathrm{p}}\right) \mathrm{U}\left(\mathrm{x}_{\mathrm{p}}, \mathrm{y}_{\mathrm{p}}\right) & \\
= & \int_{\Gamma}\left[\mathrm{U}(\mathrm{x}, \mathrm{y}) \frac{\partial}{\partial \mathrm{n}}\left(\mathrm{G}\left(\mathrm{x}, \mathrm{y} ; \mathrm{x}_{\mathrm{p}}, \mathrm{y}_{\mathrm{p}}\right)\right)\right. \\
& \left.-\mathrm{G}\left(\mathrm{x}, \mathrm{y} ; \mathrm{x}_{\mathrm{p}}, \mathrm{y}_{\mathrm{p}}\right) \frac{\partial}{\partial \mathrm{n}}(\mathrm{U}(\mathrm{x} . \mathrm{y}))\right] \mathrm{ds}(\mathrm{x}, \mathrm{y})
\end{aligned}
$$

Where we define

$$
=\left\{\begin{array}{c}
\beta\left(x_{p}, y_{p}\right) \\
\text { if }\left(x_{p}, y_{p}\right) \notin R U \Gamma \\
\frac{1}{2} \text { if }\left(x_{p}, y_{p}\right) \quad \text { lies on smooth part } \Gamma \\
1 \text { if }\left(x_{p}, y_{p}\right) \in R
\end{array}\right.
$$

This eqn.(3.39) contains only boundary integrals and is referred to as the general boundary integral equation. It relates the value of $U$ at some point inside the solution domain to integral expressions involving $U$ and $\frac{\partial U}{\partial n}$ over the boundary of the solution domain.

\subsection{Numerical discretization of the BIE}

We transform the integral eqn.( (3.39) into a system of algebraic equations. The boundary $\Gamma$ is discretized into $\mathrm{N}$ small straight line elements $\Gamma^{(1)}, \Gamma^{(2)}, \ldots \ldots, \Gamma^{(\mathrm{N}-1)}$ and $\Gamma^{(\mathrm{N})}$

$$
\text { i.e } \Gamma \simeq \Gamma^{(1)} \mathrm{U} \Gamma^{(2)} \mathrm{U} \ldots \ldots \ldots . \mathrm{U} \Gamma^{(\mathrm{N}-1)} \mathrm{U} \Gamma^{(\mathrm{N})}
$$

These straight lines are called boundary elements. The centre of each element is referred to as a collocation node.

To construct the boundary elements, we put $\mathrm{N}$-well spaced out

$\left(\mathrm{x}^{(1)}, \mathrm{y}^{(1)}\right),\left(\mathrm{x}^{(2)}, \mathrm{y}^{(2)}\right), \ldots \ldots \ldots,\left(\mathrm{x}^{(\mathrm{N}-1)}, \mathrm{y}^{(\mathrm{N}-1)}\right)$ and

points

$\left(\mathrm{x}^{(\mathrm{N})}, \mathrm{y}^{(\mathrm{N})}\right)$ on $\Gamma$,in the order given following counter clockwise direction.

Defining $\left(\mathrm{x}^{(\mathrm{N}+1)}, \mathrm{y}^{(\mathrm{N}+1)}\right)=\left(\mathrm{x}^{(1)}, \mathrm{y}^{(1)}\right)$, we take $\Gamma^{(\mathrm{k})}$ to be the boundary element from $\left(\mathrm{x}^{(\mathrm{k})}, \mathrm{y}^{(\mathrm{k})}\right)$ to $\left(\mathrm{x}^{(\mathrm{k}+1)}, \mathrm{y}^{(\mathrm{k}+1)}\right)$ for $\mathrm{k}=1,2, \ldots \ldots \ldots, \mathrm{N}$

For approximation of $U$ and $\frac{\partial U}{\partial n}$ on the boundary $\Gamma$,we assume that these functions are constants over each of the boundary elements. Specifically, we make the approximation:

$$
\begin{aligned}
& \mathrm{U} \simeq \overline{\mathrm{U}}^{(\mathrm{k})} \text { and } \frac{\partial \mathrm{U}}{\partial \mathrm{n}}=\overline{\mathrm{P}}^{(\mathrm{K})} \text { for }(\mathrm{x}, \mathrm{y}) \\
& \in \Gamma^{(\mathrm{k})}(\mathrm{k}=1,2, \ldots \ldots \ldots, \mathrm{N})
\end{aligned}
$$

where $\overline{\mathrm{U}}^{(\mathrm{k})}$ and $\overline{\mathrm{P}}^{(\mathrm{K})}$ are respectively the values of $\mathrm{U}$ and $\frac{\partial \mathrm{U}}{\partial \mathrm{n}}$ at the mid-point of $\Gamma^{(\mathrm{k})}$.

With equations (3.41) and (3.42), eqn.(3.39) can be written as

$$
\begin{aligned}
\beta\left(x_{p}, y_{p}\right) U\left(x_{p}, y_{p}\right) & \\
& =\sum_{k=1}^{N}\left\{\bar{U}^{(k)} F_{2}{ }^{(k)}\left(x_{p}, y_{p}\right)\right. \\
& \left.-\bar{P}^{(K)} F_{1}{ }^{(k)}\left(x_{p}, y_{p}\right)\right\}
\end{aligned}
$$

\section{Volume 6 Issue 7, July 2017 www.ijsr.net}




\section{International Journal of Science and Research (IJSR) \\ ISSN (Online): 2319-7064 \\ Index Copernicus Value (2015): 78.96 | Impact Factor (2015): 6.391}

where

$$
\begin{aligned}
& F_{1}{ }^{(k)}\left(x_{p}, y_{p}\right)=\int_{\Gamma^{(k)}} G\left(x, y ; x_{p}, y_{p}\right) d s(x, y) \\
& F_{2}{ }^{(k)}\left(x_{p}, y_{p}\right) \\
= & \int_{\Gamma^{(k)}} \frac{\partial}{\partial \mathrm{n}}\left[G\left(x, y ; x_{p}, y_{p}\right)\right] d s(x, y)
\end{aligned}
$$

For a given $k$, either $\overline{\mathrm{U}}^{(\mathrm{k})}$ or $\overline{\mathrm{P}}^{(\mathrm{K})}$ is known from the boundary conditions in eqn.(3.04). Thus, there are $\mathrm{N}$ unknowns constants on the right hand side of eqn.(3.43). To determine their values, we have to generate $\mathrm{N}$ equations containing the unknowns.

We let $\left(x_{p}, y_{p}\right)$ in eqn.(3.43) be given in turn by the mid points of $\Gamma^{(1)}, \Gamma^{(2)}, \ldots \ldots, \Gamma^{(\mathrm{N}-1)}$ and $\Gamma^{(\mathrm{N})}$ and obtain;

$$
\begin{aligned}
& \frac{1}{2} \overline{\mathrm{U}}^{(\mathrm{m})} \\
& =\sum_{\mathrm{k}=1}^{\mathrm{N}}\left\{\overline{\mathrm{U}}^{(\mathrm{k})} \mathrm{F}_{2}{ }^{(\mathrm{k})}\left(\overline{\mathrm{x}}^{(\mathrm{m})}, \overline{\mathrm{y}}^{(\mathrm{m})}\right)\right. \\
& \left.-\overline{\mathrm{P}}^{(\mathrm{k})} \mathrm{F}_{1}{ }^{(\mathrm{k})}\left(\overline{\mathrm{x}}^{(\mathrm{m})}, \overline{\mathrm{y}}^{(\mathrm{m})}\right)\right\}
\end{aligned}
$$

for $\mathrm{m}$

$=1,2, \ldots \ldots \ldots, \mathrm{N}$, and $\left(\overline{\mathrm{x}}^{(\mathrm{m})}, \overline{\mathrm{y}}^{(\mathrm{m})}\right)$ is the mid point of $\Gamma^{(\mathrm{m})}$ In the derivation of eqn.(3.45), we take $\beta\left(\bar{x}^{(m)}, \bar{y}^{(m)}\right)=\frac{1}{2}$, since $\left(\overline{\mathrm{x}}^{(\mathrm{m})}, \overline{\mathrm{y}}^{(\mathrm{m})}\right)$ being the mid- point of $\Gamma^{(\mathrm{m})}$ lies on a smooth part of the approximate boundary i.e.

$\Gamma^{(1)} \mathrm{U} \Gamma^{(2)} \mathrm{U} \ldots \ldots \ldots . \mathrm{U} \Gamma^{(\mathrm{N}-1)} \mathrm{U} \Gamma^{(\mathrm{N})}$.

Eqn.(3.45) constitutes a system of $\mathrm{N}$ linear algebraic equations containing the $\mathrm{N}$ unknowns on the right hand side of eqn.(3.43). Since both $\overline{\mathrm{U}}^{(\mathrm{k})}$ and $\overline{\mathrm{P}}^{(\mathrm{K})}$ contain known as well as unknown boundary data, it is necessary to write the equations with all unknowns appearing on one side as given below.

$\sum_{\mathrm{k}=1}^{\mathrm{N}} \mathrm{a}^{(\mathrm{mk})} \mathrm{Z}^{(\mathrm{k})}$

$=\sum_{\mathrm{k}=1}^{\mathrm{N}} \mathrm{b}^{(\mathrm{mk})}$ for $\mathrm{m}$

$=1,2, \ldots \ldots \ldots, \mathrm{N}$

wherea ${ }^{(\mathrm{mk})}, \mathrm{b}^{(\mathrm{mk})}$ and $\mathrm{Z}^{(\mathrm{k})}$ are defined by $\mathrm{a}^{(\mathrm{mk})}$

$=\left\{\begin{array}{c}-\mathrm{F}_{1}{ }^{(\mathrm{k})}\left(\overline{\mathrm{x}}^{(\mathrm{m})}, \overline{\mathrm{y}}^{(\mathrm{m})}\right) \text { if } \mathrm{U} \text { is specified over } \Gamma^{(\mathrm{k})} \\ \mathrm{F}_{2}{ }^{(\mathrm{k})}\left(\overline{\mathrm{x}}^{(\mathrm{m})}, \overline{\mathrm{y}}^{(\mathrm{m})}\right)-\frac{1}{2} \delta^{(\mathrm{mk})} \text { if } \frac{\partial \mathrm{U}}{\partial \mathrm{n}} \text { is specified over } \Gamma^{(\mathrm{k})}\end{array}\right.$

$$
\mathrm{b}^{(\mathrm{mk})}
$$$$
=\left\{\begin{array}{c}
\overline{\mathrm{U}}^{(\mathrm{k})}\left(-\mathrm{F}_{2}{ }^{(\mathrm{k})}\left(\overline{\mathrm{x}}^{(\mathrm{m})}, \overline{\mathrm{y}}^{(\mathrm{m})}\right)+\frac{1}{2} \delta^{(\mathrm{mk})}\right) \text { if } \mathrm{U} \text { is specified over } \Gamma^{(\mathrm{k})} \\
\overline{\mathrm{P}}^{(\mathrm{k})} \mathrm{F}_{1}{ }^{(\mathrm{k})}\left(\overline{\mathrm{x}}^{(\mathrm{m})}, \overline{\mathrm{y}}^{(\mathrm{m})}\right) \text { if } \frac{\partial \mathrm{U}}{\partial \mathrm{n}} \text { is specified over } \Gamma^{(\mathrm{k})}
\end{array}\right.
$$$$
\delta^{(\mathrm{mk})}
$$$$
=\left\{\begin{array}{l}
0 \text { if } m \neq k \\
1 \text { if } m=k
\end{array}\right.
$$

$$
\mathrm{Z}^{(\mathrm{k})}=\left\{\begin{array}{c}
\overline{\mathrm{P}}^{(\mathrm{k})} \text { if } \mathrm{U} \text { is specified over } \Gamma^{(\mathrm{k})} \\
\overline{\mathrm{U}}^{(\mathrm{k})} \text { if } \frac{\partial \mathrm{U}}{\partial \mathrm{n}} \text { is specified over } \Gamma^{(\mathrm{k})}
\end{array}\right.
$$

We notice that by collocating the load point $\mathrm{U}\left(\mathrm{x}_{\mathrm{p}}, \mathrm{y}_{\mathrm{p}}\right)$ with the nodes $\mathrm{k}=1, \ldots \ldots \ldots \ldots, \mathrm{N}$, the we get $\mathrm{N}$ system of equations.

The diagonal elements of the matrices containsingular integrals because the distance vanishes at the nodes. All other matrix elements contain regular integrals. We note that $\mathrm{Z}^{(1)}, \mathrm{Z}^{(2)}, \ldots \ldots \ldots \ldots, \mathrm{Z}^{(\mathrm{N}-1)}$ and $\mathrm{Z}^{(\mathrm{N})}$ are the $\mathrm{N}$ unknown constants on the right hand side of eqn.(3.43), while $\mathrm{a}^{(\mathrm{mk})}$ and $\mathrm{b}^{(\mathrm{mk})}$ are known coefficients.

Once eqn. (3.46) is solved for the unknowns $\mathrm{Z}^{(1)}, \mathrm{Z}^{(2)}, \ldots \ldots \ldots \ldots, \mathrm{Z}^{(\mathrm{N}-1)}$ and $\mathrm{Z}^{(\mathrm{N})}$, the values of $U$ and $\frac{\partial U}{\partial \mathrm{n}}$ over the element $\Gamma^{(\mathrm{k})}$, as given by $\bar{U}^{(\mathrm{k})}$ and $\overline{\mathrm{P}}^{(\mathrm{k})}$ respectively, are known for

$\mathrm{k}$

$=1,2, \ldots \ldots \ldots \ldots, \mathrm{N}$

Eqn.(3.43) with $\beta\left(x_{p}, y_{p}\right)=1$ provides us with an explicit formula for computing $U$ in the interior of $R$ i.e.

$$
\begin{aligned}
\mathrm{U}\left(\mathrm{x}_{\mathrm{p}}, \mathrm{y}_{\mathrm{p}}\right) \simeq \sum_{\mathrm{k}=1}^{\mathrm{N}} & \left\{\overline{\mathrm{U}}^{(\mathrm{k})} \mathrm{F}_{2}{ }^{(\mathrm{k})}\left(\mathrm{x}_{\mathrm{p}}, \mathrm{y}_{\mathrm{p}}\right)\right. \\
& \left.-\overline{\mathrm{P}}^{(\mathrm{K})} \mathrm{F}_{1}{ }^{(\mathrm{k})}\left(\mathrm{x}_{\mathrm{p}}, \mathrm{y}_{\mathrm{p}}\right)\right\} \text { for }\left(\mathrm{x}_{\mathrm{p}}, \mathrm{y}_{\mathrm{p}}\right) \\
& \in \mathrm{R}
\end{aligned}
$$

The integrals (3.44) can be evaluated analytically and their expressions are given by:

$$
\begin{aligned}
& \mathrm{F}_{1}{ }^{(\mathrm{k})}\left(\mathrm{x}_{\mathrm{p}}, \mathrm{y}_{\mathrm{p}}\right)=\frac{\ell^{(\mathrm{k})}}{2 \pi}\left\{\ln \left(\ell^{(\mathrm{k})}\right)\right. \\
&+\left(1+\frac{\mathrm{B}^{(\mathrm{k})}\left(\mathrm{x}_{\mathrm{p}}, \mathrm{y}_{\mathrm{p}}\right)}{\left.2 \mathrm{~A}^{(\mathrm{k})}\right) \ln \mid 1}\right. \\
&++\frac{\mathrm{B}^{(\mathrm{k})}\left(\mathrm{x}_{\mathrm{p}}, \mathrm{y}_{\mathrm{p}}\right)}{2 \mathrm{~A}^{(\mathrm{k})}} \mid \\
&\left.-\frac{\mathrm{B}^{(\mathrm{k})}\left(\mathrm{x}_{\mathrm{p}}, \mathrm{y}_{\mathrm{p}}\right)}{2 \mathrm{~A}^{(\mathrm{k})}} \ln \left|\frac{\mathrm{B}^{(\mathrm{k})}\left(\mathrm{x}_{\mathrm{p}}, \mathrm{y}_{\mathrm{p}}\right)}{2 \mathrm{~A}^{(\mathrm{k})}}\right|-1\right\} \\
& \text { for } 4 \mathrm{~A}^{(\mathrm{k})} \mathrm{E}^{(\mathrm{k})}\left(\mathrm{x}_{\mathrm{p}}, \mathrm{y}_{\mathrm{p}}\right)-\left[\mathrm{B}^{(\mathrm{k})}\left(\mathrm{x}_{\mathrm{p}}, \mathrm{y}_{\mathrm{p}}\right)\right]^{2} \\
&=0
\end{aligned}
$$

and

$\mathrm{F}_{1}^{(\mathrm{k})}\left(\mathrm{x}_{\mathrm{p}}, \mathrm{y}_{\mathrm{p}}\right)=$

$\frac{e^{(k)}}{4 \pi}\left\{2\left[\ln \left(\ell^{(k)}\right)-1\right]-\frac{B^{(k)}\left(x_{p}, y_{p}\right)}{2 A^{(k)}} \ln \left|\frac{B^{(k)}\left(x_{p}, y_{p}\right)}{2 A^{(k)}}\right|+\right.$

1+Bkxp,yp2Akln1+Bkxp,ypAk+Ekxp,ypAk+4AkEkxp,yp -Bkxp,yp2Ak $\times \arctan 2 A k+B k x p, y p 4 A k E k x p, y p-B k x p, y$ p2-arctanBkxp,yp4AkEkxp,yp-Bkxp,yp2
On the other hand,

$$
\begin{gathered}
\mathrm{F}_{2}{ }^{(\mathrm{k})}\left(\mathrm{x}_{\mathrm{p}}, \mathrm{y}_{\mathrm{p}}\right)=0 \quad \text { for } 4 \mathrm{~A}^{(\mathrm{k})} \mathrm{E}^{(\mathrm{k})}\left(\mathrm{x}_{\mathrm{p}}, \mathrm{y}_{\mathrm{p}}\right)-\left[\mathrm{B}^{(\mathrm{k})}\left(\mathrm{x}_{\mathrm{p}}, \mathrm{y}_{\mathrm{p}}\right)\right]^{2} \\
=0
\end{gathered}
$$

And

\section{Volume 6 Issue 7, July 2017 www.ijsr.net}




\section{International Journal of Science and Research (IJSR)}

ISSN (Online): 2319-7064

Index Copernicus Value (2015): 78.96 | Impact Factor (2015): 6.391

$$
\begin{aligned}
& \mathrm{F}_{2}{ }^{(\mathrm{k})}\left(\mathrm{x}_{\mathrm{p}}, \mathrm{y}_{\mathrm{p}}\right) \\
& =\frac{\ell^{(\mathrm{k})}\left[\mathrm{n}_{\mathrm{x}}{ }^{(\mathrm{k})}\left(\mathrm{x}^{(\mathrm{k})}-\mathrm{x}_{\mathrm{p}}\right)+\mathrm{n}_{\mathrm{y}}{ }^{(\mathrm{k})}\left(\mathrm{y}^{(\mathrm{k})}-\mathrm{y}_{\mathrm{p}}\right)\right]}{\pi \sqrt{4 \mathrm{~A}^{(\mathrm{k})} \mathrm{E}^{(\mathrm{k})}\left(\mathrm{x}_{\mathrm{p}}, \mathrm{y}_{\mathrm{p}}\right)-\left[\mathrm{B}^{(\mathrm{k})}\left(\mathrm{x}_{\mathrm{p}}, \mathrm{y}_{\mathrm{p}}\right)\right]^{2}}} \\
& \times\left[\arctan \left(\frac{2 \mathrm{~A}^{(\mathrm{k})}+\mathrm{B}^{(\mathrm{k})}\left(\mathrm{x}_{\mathrm{p}}, \mathrm{y}_{\mathrm{p}}\right)}{\sqrt{4 \mathrm{~A}^{(\mathrm{k})} \mathrm{E}^{(\mathrm{k})}\left(\mathrm{x}_{\mathrm{p}}, \mathrm{y}_{\mathrm{p}}\right)-\left[\mathrm{B}^{(\mathrm{k})}\left(\mathrm{x}_{\mathrm{p}}, \mathrm{y}_{\mathrm{p}}\right)\right]^{2}}}\right)\right. \\
& \left.-\arctan \left(\frac{\mathrm{B}^{(\mathrm{k})}\left(\mathrm{x}_{\mathrm{p}}, \mathrm{y}_{\mathrm{p}}\right)}{\sqrt{4 \mathrm{~A}^{(\mathrm{k})} \mathrm{E}^{(\mathrm{k})}\left(\mathrm{x}_{\mathrm{p}}, \mathrm{y}_{\mathrm{p}}\right)-\left[\mathrm{B}^{(\mathrm{k})}\left(\mathrm{x}_{\mathrm{p}}, \mathrm{y}_{\mathrm{p}}\right)\right]^{2}}}\right)\right] \\
& >0 \\
& \text { for } 4 \mathrm{~A}^{(\mathrm{k})} \mathrm{E}^{(\mathrm{k})}\left(\mathrm{x}_{\mathrm{p}}, \mathrm{y}_{\mathrm{p}}\right)-\left[\mathrm{B}^{(\mathrm{k})}\left(\mathrm{x}_{\mathrm{p}}, \mathrm{y}_{\mathrm{p}}\right)\right]^{2}
\end{aligned}
$$

where $\mathrm{A}^{(\mathrm{k})}=\left[\ell^{(\mathrm{k})}\right]^{2}, \mathrm{~B}^{(\mathrm{k})}\left(\mathrm{x}_{\mathrm{p}}, \mathrm{y}_{\mathrm{p}}\right)=\left[-\mathrm{n}_{\mathrm{y}}{ }^{(\mathrm{k})}\left(\mathrm{x}^{(\mathrm{k})}-\mathrm{x}_{\mathrm{p}}\right)+\right.$ nxkyk-yp $2 \ell \mathrm{k}$

$$
\begin{aligned}
\mathrm{E}^{(\mathrm{k})}\left(\mathrm{x}_{\mathrm{p}}, \mathrm{y}_{\mathrm{p}}\right)=\left(\mathrm{x}^{(\mathrm{k})}-\mathrm{x}_{\mathrm{p}}\right)^{2} & \\
& +\left(\mathrm{y}^{(\mathrm{k})}\right. \\
& \left.-\mathrm{y}_{\mathrm{p}}\right)^{2}, \text { and } \ell^{(\mathrm{k})} \text { is the length of } \Gamma^{(\mathrm{k})} \\
\ell^{(\mathrm{k})} &
\end{aligned}
$$

is the nornal vector to $\Gamma^{(\mathrm{k})}$ pointing away from $\mathrm{R}$

\section{Methods of Solution and Discussion of Results}

This chapter presents computation and discussion of results on heat distribution in bounded region $\mathrm{R}$ obtained using BEM and analytical solution. Rearranging eqn(3.48)according to the specified conditions, we develop BEM code for the computation of the solution. We now consider a 2-D square domain; with aspect ratio 1:1. Inside this square is a square pipe with dimensions $0.4 \times 0.4$. Temperature and fluxes are specified on some boundaries. The remaining boundary values are computed with our numerical model and the results compared to the analytical solution to test the accuracy and efficiency of BEM.

The following results were obtained when BEM is implemented with the help of FORTRAN 95 software using the three types of boundary conditions and different boundary discretization nodes.

\section{CASE 1}

When non-homogeneous Neumann boundary conditions are specified on both the outer and inner boundaries the results of temperature are computed and illustrated in the diagram below for $\mathrm{N}=24$ Nodes.

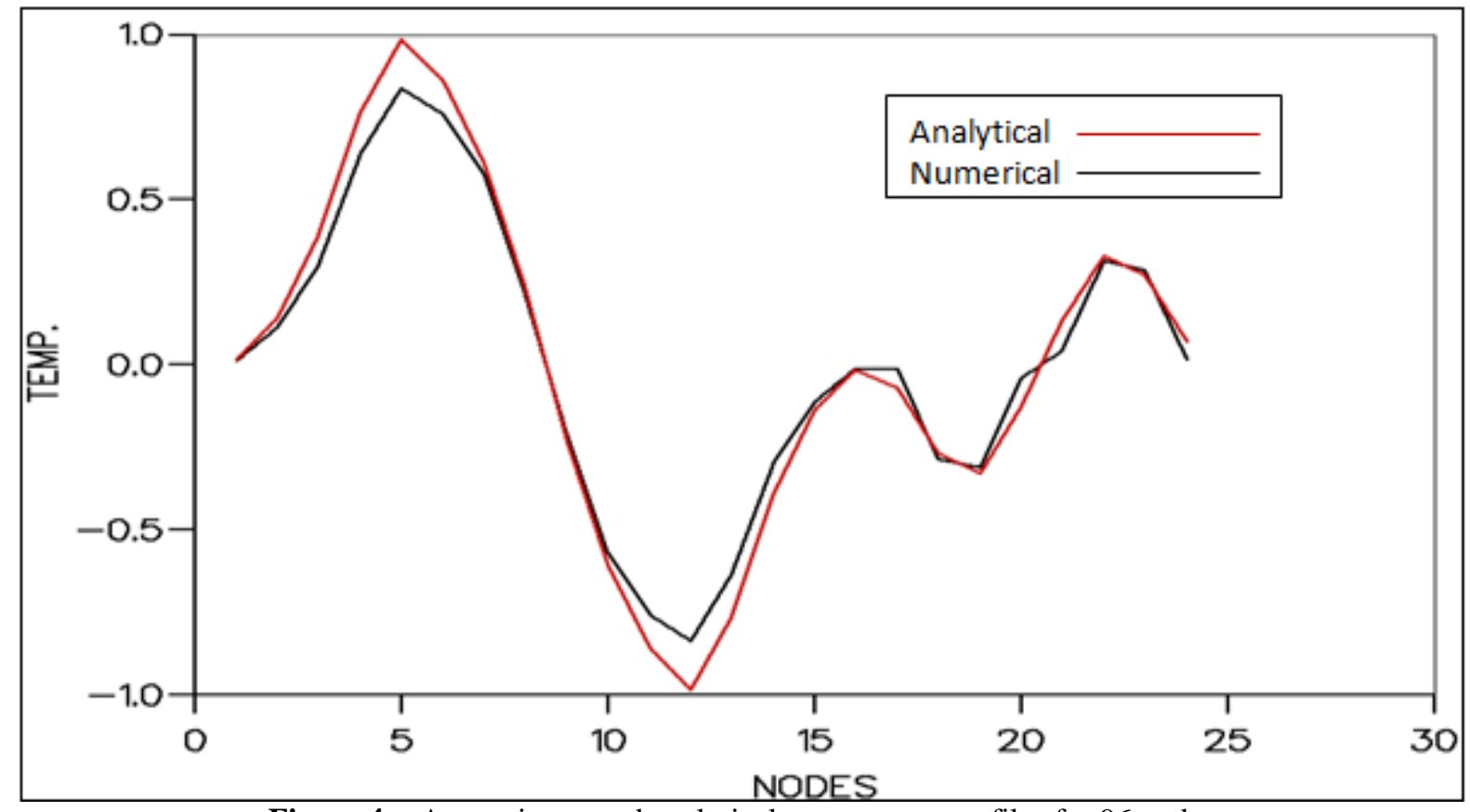

Figure 4a: Approximate and analytical temperature profiles for 96 nodes

\section{Case 2}

When non-homogeneous Neumann boundary and Diritchlet boundary conditions are specified on both the outer and inner boundaries respectively the results of temperature are computed and illustrated in the diagram below for $\mathrm{N}=16$ Nodes. 


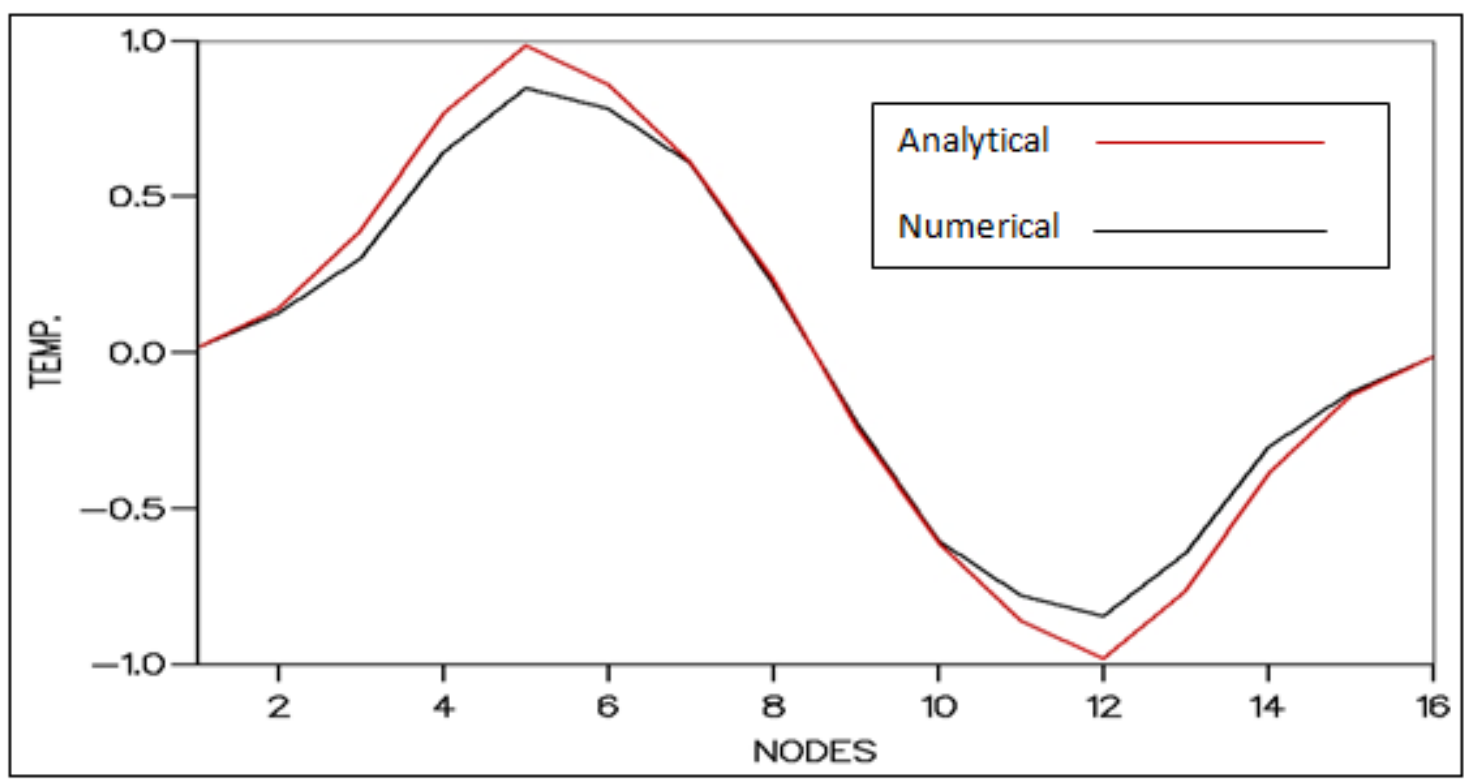

Figure 4b: Approximate and analytical temperature profiles for 16 nodes on the outer boundary.

boundaries respectively the results of temperature are

When non-homogeneous Neumann and Diritchlet boundary computed and illustrated in the diagram below for $\mathrm{N}=64$ conditions are specified on both the outer and inner Nodes.

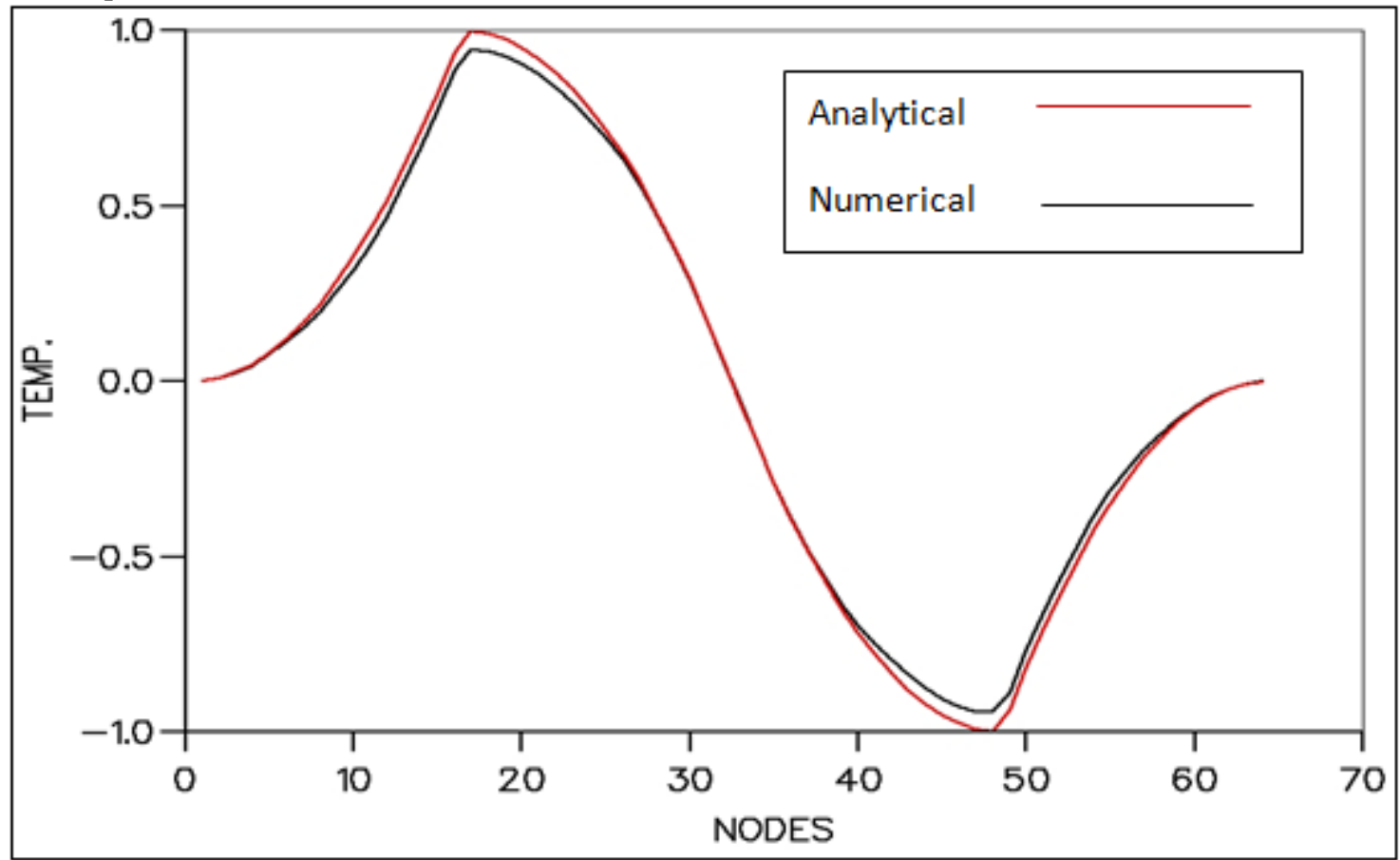

Figure 4c: Approximate and analytical temperature profiles for 64 nodes on the outer boundary.

\section{Case 3}

When non-homogeneous Neumann boundary and Diritchlet boundary conditions are specified on both the inner and outer boundaries respectively the results of flux are computed and illustrated in the diagram below for $\mathrm{N}=64$ Nodes. 


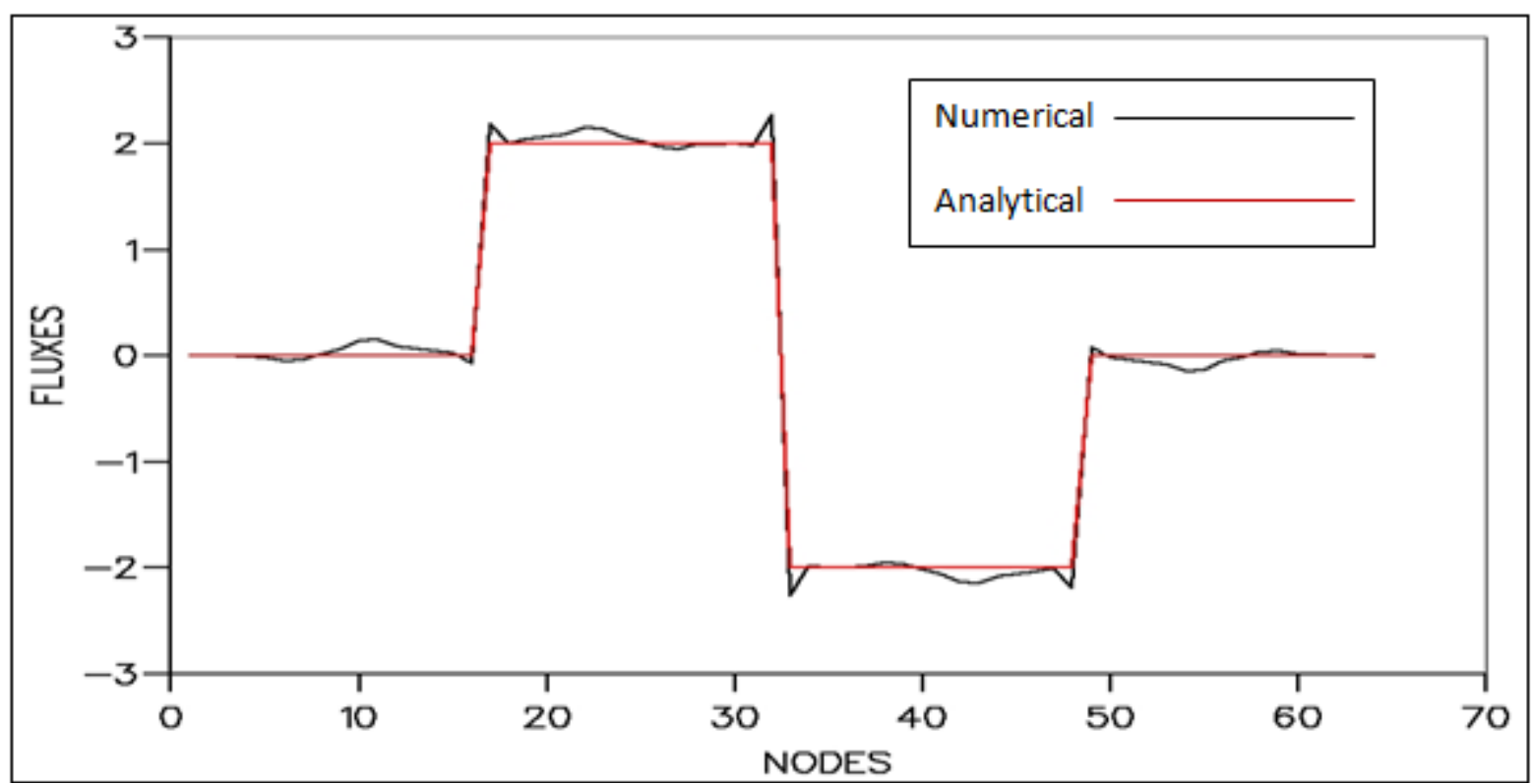

Figure 4d: Approximate and analytical flux profiles for 64 nodes on the outer boundary

\section{Case 4}

When fluxes are specified in the $2^{\text {nd }}, 3^{\text {rd }}, 5^{\text {th }}$, and $8^{\text {th }}$ boundaries while the temperature is specified on the other remaining boundaries (Chauchy boundary conditions given). The results at various nodes in the solution domain are computed and some results tabulated as below.

Table 1

\begin{tabular}{|c|l|l|l|}
\hline$\left(x_{p}, y_{p}\right)$ & 24 Elements & 96 Elements & Exact \\
\hline$(0.8,0.9)$ & -0.1609602 & -0.1641215 & -0.170000 \\
\hline$(0.6,0.9)$ & -0.4223961 & -0.4307708 & -0.450000 \\
\hline$(0.952,0.85)$ & 0.1610184 & 0.1815919 & 0.1838040 \\
\hline$(0.82,0.96)$ & -0.2212187 & -0.246075 & -0.249000 \\
\hline$(0.125,0.875)$ & -0.6750384 & -0.7038109 & -0.750000 \\
\hline
\end{tabular}

\subsection{Discussion of the Results}

The temperature distribution around a square pipe presents a sine curve. This is in agreement with research carried outby Yan and Wei[12] on the impact of soil and pipe thermal conductivities on performance of horizontal buried pipe. They made a conclusion that soil temperature distribution around a buried circular pipe presents a sine curve regardless of the soil and pipe thermal conductivities.

Case 2 shows temperature profiles for 16 and 64 number of boundary elements respectively. The comparison between the analytical and numerical shows that for the Diritchletvariable U, even coarse discretization leads to good accuracy. The curve appears smooth after the number of nodes is increased.

Case 3 shows the flux profiles for 64 number of boundary elements respectively. The finer discretization by 64 elements shows convergence of numerical solution to that of analytical solution.

In case 4, we have Cauchy boundary conditions at inner and outer boundaries. A few nodes taken within the solution domain were compare to the analytical solutions. It's evident that the numerical solution approached the analytical solution when the number of boundary elements were increased.

\section{Conclusion}

In this study, we have demonstrated that the BEM is a very powerful technique to solve steady state heat equation. The circular geometry was transformed to square through linear transformation. The collocation method is utilized. BEM code was developed. The mathematical software FORTRAN 95 was used to compute results and graphs were drawn at various nodes of discretization using G-Sharp. Two test problems were used. The temperature and flux profiles were close to the analytical profile. The effect of increasing the number of boundary elements resulted in high convergence. The numerical values of temperature within the solution domain were in agreement with the analytical solution especially when the nodes are increased.

\section{References}

[1] A. J. Nowak and C. A. Brebbia, "Solving Helmholtz equation by Multiple reciprocity method" in computer and experiments in fluids flow (eds G.M Carlomagno and C.A. Brebbia), (comput.,southampton, 1989) 265270

[2] F.J. Rizzo. An integral equation approach to boundaryvalue problems of classical elastostatics. Q. Appl. Math., 25:83-95, 1967.

[3] Fourier,J. ThéorieAnalytique de la Chaleur. Paris, Didot, 1822.

[4] Fredholm. Sur uneclassed'equationsfonctionnelles. ActaNumer., 27:365-390, 1903.

[5] Gardano P and Dabnichki.P (2006) Application of Boundary Element Method to modeling of Added mass and its effect on hydrodynamic forces, CMES, 15,87-98.

[6] G.T. Symm. Integral equation methods in potential theory - ii, Series A. Proc.Roy. Soc. Lond., 275:33-46, 1963 


\section{International Journal of Science and Research (IJSR) \\ ISSN (Online): 2319-7064}

Index Copernicus Value (2015): 78.96 | Impact Factor (2015): 6.391

[7] H. Bau and S. Sadhal: Heat Losses from Fluid Flowing in a Buried Pipe, International Journal of Heat and Mass Transfer, Vol 25, Issue 11, pp 1621-1629 (1982).

[8] M.A. Jaswon. Integral equation methods in potential theory - i, Series A. Proc.Roy. Soc. Lond., 275:23-32, 1963

[9] M. Chung, P. Jung and R. Rangel: Semi-analytical solution for heat transfer from a buried pipe with convection on the exposed surface, International Journal of Heat and Mass Transfer, Vol 42, pp 3771-3786 (1999).

[10] Ozisik M.N,1989,Boundary Value Problems of Heat Conduction, Dover publications, Inc-31 East $2^{\text {nd }}$ Street, Mine Ola, N.Y 11501 USA page 211-215.

[11]Parag V., Krishna J.S.V.R.(2013) "Numerical solution for two dimensional Laplace equation with Diritchlet boundary conditions", e-ISSN:2278-5728,PISSN:,Vol6,pp 66-75.

[12] Yan song,wei $\mathrm{Na}(2006)$ Thesis on impact of soil and pipe thermal conductivity on performance of horizontal buried pipe, Harbin Institute of Technology, China.

Volume 6 Issue 7, July 2017 www.ijsr.net 